\title{
Effects of National Macroeconomic Variables and Political Condition on Dhaka Stock Exchange
}

\author{
Md. Nazmus Sakib, Mohammad Zubair Hossain* \\ Dept. of Accounting \& Finance, North South University, Dhaka, Bangladesh \\ Email address: \\ sakibnil@gmail.com (Md. N. Sakib), zubairhossain@gmail.com (M. Z. Hossain) \\ To cite this article: \\ Md. Nazmus Sakib, Mohammad Zubair Hossain. Effects of National Macroeconomic Variables and Political Condition on Dhaka Stock \\ Exchange. Journal of Finance and Accounting. Vol. 3, No. 2, 2015, pp. 28-34. doi: 10.11648/j.jfa.20150302.12
}

\begin{abstract}
National macroeconomic variables which are determined by economic policies taken by the authority and aggregated economic activities of individuals, has definitive infuence on a country's stock market. Prime share market of Bangladesh, Dhaka Stock Exchange is also shaped by local macroeconomic situation. Additionally, country's political condition might affect the market as well because as a developing economy our market face significant political instability. It is observed that the mean point value of the DSE general index was slightly lower for observations when the country goes through political instability than for observations when the political situation was stable. However, this difference was not statistically significant. Our investors seem to be quite indifferent to the country's political condition and do not turn their back to the market just because the country was observing political unrest. Correlation analysis reveals that all the macroeconomic variables are moderately correlated with DGEN while money supply, remittance and IRS are significantly correlated. Money supply, remittance, inflation rate and exchange rate are positively related with the general index when interest rate spread and political unrest shows negative relationship. This relationship is justifiable by the economic fundamentals. Both money supply and remittance inject cash into the economy, which is supposed to be distributed in all sectors, and thus the stock market would naturally grow. Higher IRS means the banks and other financial institutions are better off by just lending money and would be less interested in investing in the capital markets. Two economic models (linear \& binomial) are derived to explain this relationship and estimate the DGEN using the macroeconomic variables. Among the two derived models, the binomial one estimate the general index way better than the linear model (in terms of regression R-square) and is able to explain more than $80 \%$ of the fluctuations in Dhaka Stock Exchange where the linear model explains only $25 \%$ of the fluctuations. Additionally, another correlation analysis, which is carried out after dropping 5 observations when the market observed unusual ups \& downs, shows stronger relationships for all variables. Both estimation models explain more of the fluctuations when derived from the engineered dataset. It can be assumed that external force(s) manipulated the market during that time. However, our study cannot draw any definitive conclusion regarding those 5 months of massive fluctuations because there is always a chance that this happened due randomness which is inherited by the stock market like any other system.
\end{abstract}

Keywords: Macroeconomics Variables, Political Conditions, Dhaka Stock Exchange

\section{Introduction}

The stock market is one of the most vital components of a free-market economy. It provides companies with access to capital in exchange for giving investors a slice of ownership in the company. The stock market lets investors grow small initial sums of money into large ones and become rich without taking the risk of starting a business or making the sacrifices that may accompany a high-paying career.

The stock market lets investors participate in the financial achievements of the companies whose shares they hold.
When companies are profitable, stock market investors make money through the dividends the companies pay out and by selling appreciated stocks at a profit called a capital gain. The downside is that investors can lose money if the companies whose stocks they hold lose money, the stock prices go down and the investor sells the stocks at a loss.

The stock market can be split into two main sections: the primary market and the secondary market. The primary market is where new issues are first sold through initial 
public offerings. Institutional investors typically purchase most of these shares from investment banks. All subsequent trading goes on in the secondary market where participants include both institutional and individual investors. (1)

Stocks can be categorized in various ways. One common way is by the country where the company is domiciled. For example, Apex footwear is domiciled in Bangladesh, so they may be considered as a part of the Bangladeshi stock market, although their stock may also be traded on exchanges in other countries. At the close of 2012, the size of the world stock market (total market capitalization) was about $\$ 55$ trillion. By country, the largest market was the United States (about $34 \%$ ), followed by Japan (about 6\%) and the United Kingdom (about 6\%).

On the other hand, the stock exchange is a place to trade stocks. Companies may want to get their stock listed on a stock exchange. Other stocks may be traded "over the counter", that is, through a dealer. A large company will usually have its stock listed on many exchanges across the world. In Bangladesh we have two stock exchanges; Dhaka Stock Exchange (DSE) \& Chittagong Stock Exchange (CSE).

The Dhaka Stock Exchange is located in Motijheel, Dhaka. It is the major of the two stock exchanges in the country. Dhaka Stock Exchange (DSE) itself is a public limited company. It is formed and managed under the Company Act 1994, Security and Exchange Commission Act 1993, Security and Exchange Commission Regulation 1994, and the Security Exchange (Inside Trading) regulation 1994. The issued capital of this company is Tk. 500,000 which is divided up to 250 shares each pricing Tk. 2000. No individual or firm can buy more than one share. According to stock market rule only members can participate in the floor and can buy shares for himself or his clients. At present it has 238 members. Currently, the combined market capitalization of listed companies on the Dhaka Stock Exchange is almost 3.7 trillion taka.

The scope of our research was limited to DSE only. Like stock indices in every stock exchange all over globe, DSE index rise and fall like clockwork. However, in an efficient capital market, security prices adjust rapidly to the arrival of new information. Economic theory suggests that stock prices should reflect expectations about future corporate performance. Corporate profits generally reflect the level of economic activities. If stock prices accurately reveal the underlying fundamentals, then the stock prices should be employed as leading indicators of future economic activities. Therefore, the current prices of securities reflect all information about the security which implies the current point level of the DSE general index reflects all the information regarding national macro economics. As political instability in our country is a common phenomenon, a current political condition may also be a determining factor of stock prices.

The primary goal of the research is to reveal observable patterns in the DSE general index and its dependency with major macroeconomic variables and political condition of Bangladesh. If the average point of the general index is significantly higher when political condition is more stable than that when political crisis is present. Then the index will be analyzed against interest rate, inflation rate, money supply, exchange rate, remittances and political unrest (dummy variable) to check if they have any influence and to what extent. Finally, two economic models were derived (linear and binomial) which will reveal the precise mathematical impact of macroeconomic variable on the DSE general index. Additionally, biggest stock market crash in our history preceded by a steep climb during November 10 to February 11 will also be investigated. Therefore, our objective is (a) to investigate if the political condition of the country as political unrest dummy variable has any effect on the DSE general index, (b) to reveal how and to what extent the macroeconomic independent variables being studied influence DSE general index, (c) to derive an economic model to estimate the DSE general index from national macroeconomic variables.

\section{Research Methodology}

The research was mostly quantitative in nature. All conclusions were derived from numeric evidences. For that purpose monthly stock data and macroeconomic data of interest rate spread, inflation rate, money supply, exchange rate \& remittance were collected from secondary sources, mainly from the Bangladesh Bank's web archive. We collected only one observation per month for each indicator. For stock index, index value at the end of each month is collected. Same goes for money supply and remittance. For other variables, monthly data were readily available. However, we had to face great difficulty in gathering IRS data as Bangladesh Bank's web archive offered it from 2013 only. So I went through the internet archive (archive.org) of interest rate excel file and was able to capture 2010 and 11 . Moreover, I had to go through the print version of different monthly journals published by BB to gather the rest of the data. I produced the Political unrest dummy variable from newspapers and different people. I assumed the presence of "Political Unrest" if 5 or more people were killed during that month in a political clash. In total, 83 observations from August 2007 to June 2014 are collected for all seven variables. All data are first inputted in excel for sorting and transformation into the appropriate state. After that, the data are converted into an SPSS format for further analysis using this statistical package.

Three kinds of analysis had to be carried out: t-test for checking the hypothesis that point value of DGEN is lower when political instability exists, correlation analysis and then regression. Independent samples $t$ test in SPSS was used for testing the impact of political unrest on the DSE general index. But before that the data was tested for presence multicollinearity. For that purpose, variance inflation factor (VIF) is calculated using the proper formula for each independent variable using the r-square value which is obtained by regressing that variable against the rest of the independent variables. For VIF value higher than 10, presence 
of collinearity is assumed. Therefore that variable is dropped and the same analysis is carried out again using the rest of the explanatory variables. And multiple linear regression models for regression analysis. Our aim was to derive two different models, one is linear and another is binomial. For binomial model 5 more variables are calculated by taking a square of the 5 macroeconomic variables and then run a stepwise regression to obtain coefficients.

Money supply and remittance are entered in billion BDT. Inflation and IRS are entered into the equation as percentage points, for $10 \%$ we entered 10 not 0.10 .

\section{Results}

Over the period of 83 months, the DSE general index was appreciated by 2025 points from 2455 to 4481, while observing a lot of ups and downs. It has seen its peak in November, 2010 followed by a massive crash over the next few months. It is believed that during this time (Oct 10 to Feb 11) share market was engineered very technically to exploit the common investors out of their ignorance. However, we can observe an increasing trend in the DGEN index along with broad money supply $(\mathrm{m} 2)$ and remittance which is very common in a developing economy. Other independent variables, inflation rate, exchange rate (USD-BDT) and interest rate spread, seems to have a flatter trend line over time which indicates time is not likely to be their guiding force (figure 1).
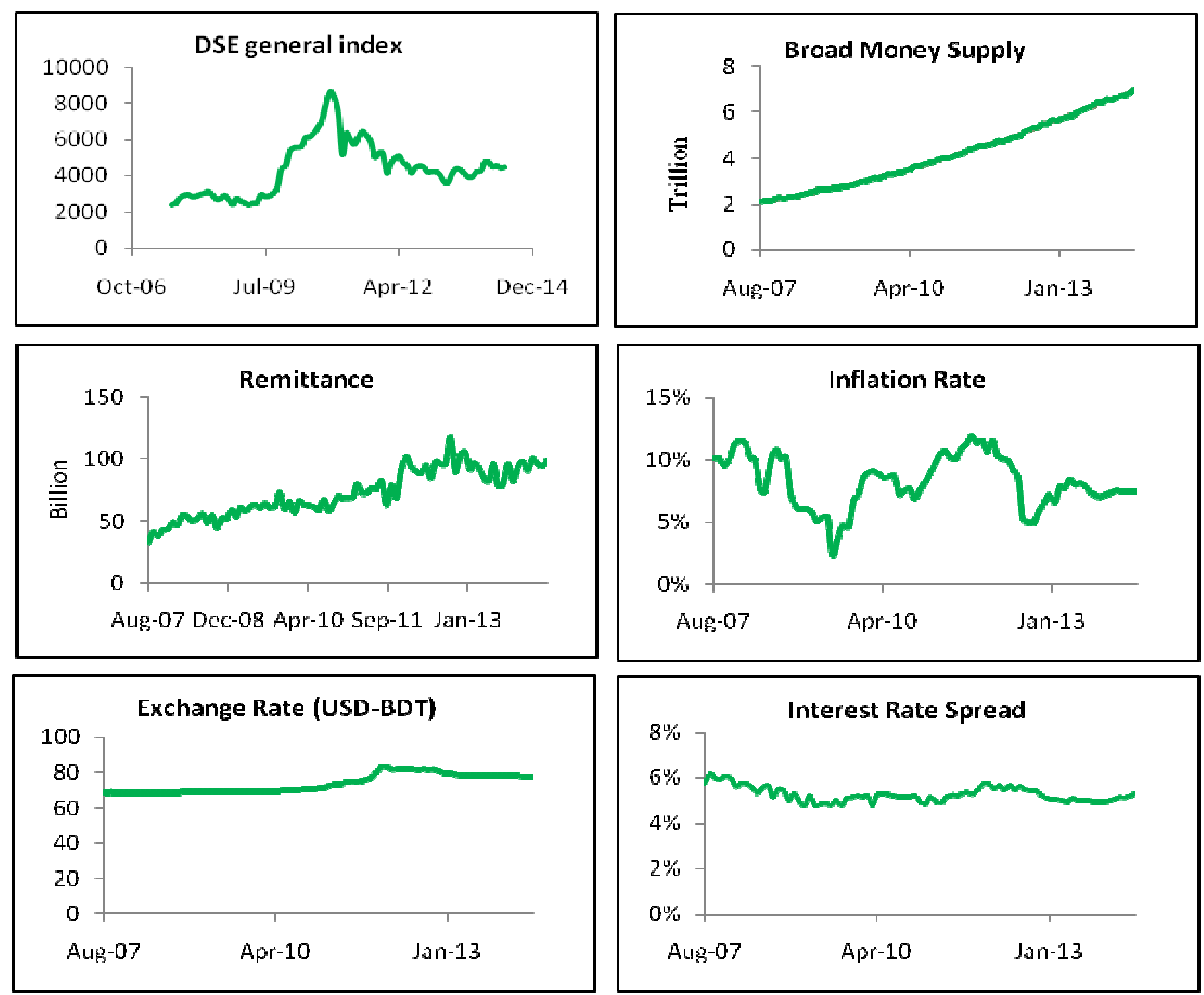

Figure 1. ups and downs in Dhaka Stock Exchange general index and national macroeconomic variables of our choice over time

Average value of DGEN was 4418 points with a standard deviation of 1469 . However, it falls to 4175 when country's political condition was unstable. For other times, DGEN index was 4464 points (Table 1). It's obvious that political instability adversely affects the market; however, we cannot say that with statistical significance before running other 
tests.

Table 1. Descriptive statistics (number of observations, mean, standard deviation, standard error) of the DSE general index as whole and distinctively for cases when country observed political unrest and when not.

\begin{tabular}{lllll}
\hline Political Unrest & N & Mean & Std. Dev & Std. Error \\
\hline Yes & 13 & 4174.80 & 270.37 & 74.99 \\
No & 70 & 4463.91 & 1593.28 & 190.43 \\
Total & 83 & 4418.63 & 1469.00 & 161.24 \\
\hline
\end{tabular}

\subsection{T-Test for Equality of Means}

The dataset can be divided into two parts using the dummy political unrest variable; one part was for cases when country observed a stable political condition and another was for observations when political unrest exists.

Although, the average value of DGEN was 289 points higher when there was no political unrest. Standard deviation was also higher. But we cannot draw any conclusion by merely looking at these statistics. For these two different conditions, the average value of the DSE general index can be compared using t-test to uncover the effects of political unrest.
But first Levene's test for equality of variance is carried out (Table 2) at a significance level of 0.05 . We are ensured that the variances of two distinct dataset are different. Therefore a t-test for equality of means is carried out without assuming equal variances.

Table 2. Levene's test for equality of variances. A significance value less than our chosen 0.05 means, variances of two samples are not equal. The test is executed in DGEN variable when political unrest is observed and when not observed.

\begin{tabular}{ll}
\hline $\mathbf{F}$ & Sig \\
\hline 19.697 & 0.000 \\
\hline
\end{tabular}

The sample evidence was not enough to conclude two means are different. P-value of 0.162 is achieved from SPSS, which is higher than 0.05 (Table 3). Thus we cannot be sure if the political condition of the country has a significant impact on investors' mind which may lead to changes in the DSE general index.

Table 3. $t$ test for equality of means between DGEN index when political unrest was observed and that when political condition was stable. Unequal variance was assumed.

\begin{tabular}{llllll}
\hline t & df & Sig (2-tailed) & Mean Difference & Std. Error Difference & \multicolumn{2}{l}{$\begin{array}{l}\text { 95\% Confidence Interval of the Difference } \\
\text { Lower }\end{array}$} \\
\hline-1.413 & 80.876 & 0.162 & -289.11 & 204.665 & Upper \\
\hline
\end{tabular}

\subsection{Correlation Analysis}

Correlation analysis is performed in SPSS to observe the extent to which the independent macroeconomic variables affect the DSE general index. Pearson correlation also reveals the nature of relationships.

Table 4 contains the correlation statistics for each independent variable with the dependent variable (DGEN) along with the level of significance. We can observe that the IRS and political unrest have a negative relationship with
DGEN while the rests have a positive correlation. Money supply, Remittance and IRS affects the index in highest magnitude and correlations for only these three variables are significant. In spite of not being significant, DGEN's correlation with inflation rate and exchange rate are significant at a relatively lower p-value $(0.098 \&$ 0.123) when political unrest has way high level of significance, that are not consider for regression analysis.

Table 4. Pearson correlation between DGEN index and the national macroeconomical variables with significance.

\begin{tabular}{lllllll}
\hline & Money Supply & Remittance & Inf. rate & Exchange rate & IRS & Political Unrest \\
\hline Pearson-Correlation & 0.312 & 0.286 & 0.183 & 0.171 & -0.222 \\
Sig. (2-tailed) & 0.004 & 0.009 & 0.098 & 0.123 & 0.043 \\
\hline
\end{tabular}

Another table for correlation is derived, only this time 5 observations from Oct 10 to Feb 11 are removed (Table 5). It is obvious that if we remove the observations when the Dhaka Stock Exchange was believed to be engineered, correlation coefficient for first four variables increases by significant amount. Quality of correlation in terms of significance also is also better. Therefore, we may assume that observations from those 5 months are anomaly in mathematical harmony.

Table 5. Pearson correlation between DGEN index and the national macroeconomic variables with significance. (observations from Oct 10 to Feb 11 removed).

\begin{tabular}{lllllll}
\hline & Money Supply & Remittance & Inf. rate & Exchange rate & IRS & Political Unrest \\
\hline Pearson-Correlation & 0.312 & 0.286 & 0.183 & 0.171 & -0.222 & -0.072 \\
Sig. (2-tailed) & 0.004 & 0.009 & 0.098 & 0.123 & 0.043 & 0.518 \\
\hline
\end{tabular}

\subsection{Regression Analysis}

As the variable political unrest is proved to not having any determining effect on the general index, this variable was not considered for regression analysis. Before performing the analysis, we must first be sure that any of the independent variables was not function of other independent variables. For this purpose, we checked for the presence of 
multicollinearity in the data, I first carried out multiple linear regression on every independent variable by the rests and stored the r-square (Goodness of fit) value. Then, using proper formula, variance inflation factor was calculated from the adjusted R2 value. Table 6 presents VIF for all independent variables. We can observe that although we have high values for remittance, exchange rate and money supply, none of them are as extreme as our chosen level of 10 . So that we can conclude that extreme multicollinearity doesn't exist in our data. Therefore, no variable needs to be removed and regression analysis can be carried out.

Table 6. Adjusted r-square values for each of the independent variables when regressed by the rests and Variation inflation factor derived from that.

\begin{tabular}{lll}
\hline Variables & Adjusted R-Square & VIF \\
\hline Money Supply & 0.841 & 3.41 \\
Remittance & 0.895 & 5.02 \\
Inflation Rate & 0.292 & 1.09 \\
Exchange Rate & 0.894 & 4.98 \\
Interest Rate Spread & 0.555 & 1.44 \\
\hline
\end{tabular}

Firstly, regression of DGEN dependent variable by independent variables of our choice (money supply, remittance, inflation rate, exchange rate \& IRS) is carried out using SPSS linear regression command. Following a linear regression equation is obtained:

DGEN $=16527+0.30 \mathrm{~m} 2+54.10 \operatorname{Rem}+320 \mathrm{Inf}-206 \mathrm{ER}-886 \mathrm{IRS}+\mathrm{e}$

All coefficients except money supply and IRS are significant. However, significance values of those two variables are not extreme enough to consider removing them from the equation. The regression equation was significant as a whole with $\mathrm{F}=6.39$ and $\mathrm{p}=0.00$ but we have a low $\mathrm{r}$-square value of 0.247 . This indicates our model can only explain $24.7 \%$ of variations in the DSE general index and rest $75 \%$ of the variations was due to randomness, modeling error or other variables that we failed to look into.

For deriving a better equation, 5 more variables are computed by taking the square of the macroeconomic independent variables. This time we have 10 independent variables against the DSE general index. Although, linear regression in SPSS is carried out, a binomial equation is achieved. Below is the regression equation:

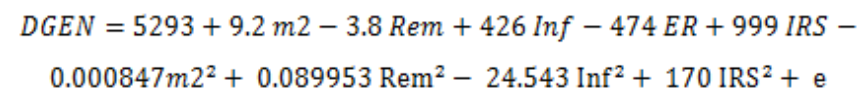

Variable "square of exchange rate" was automatically dropped by SPSS because of the high partial correlation. In spite of some insignificant coefficients, the equation is significant as a whole. This binomial equation does way better than the previous linear equation in terms of predictability. The binomial regression equation can explain $82.1 \%$ of the variations observed. Macroeconomic variables can explain the movements in Dhaka Stock Exchange quite well.

Two regression equations were also derived using the dataset, where 5 observations from Oct 10 to Feb 11 were removed. Predictability in both cases was better, $40.5 \%$ for first equation and $84.4 \%$ for the second equation.

\section{Discussion}

To gain a better insight about the subject matter of the investigation, previous researches conducted on the same field are studied. The conclusions that the researchers around the globe derived are interesting. In some countries strong relationships between macroeconomic variables and major stock indices were found when study results were insignificant in other countries.

The impact of macroeconomic was a risk of the equity market of the Philippines. The study showed that, exchange rate movements, financial fluctuations and political changes on owners of Philippine equities could not explain Philippine stock returns. However, stock prices and exchange rates do not have a long-term relationship (2). Stock indices seem to be co-integrated with the four macroeconomic variables; trade balance, industrial production, foreign exchange rate and money supply in Korean stock prices (3). In Malaysia stock prices are found to share positive long-run relationships with industrial production and CPI. On the contrary, stock prices have a negative association with money supply and exchange rate (4)

The relationship between macroeconomic variables and stock market return and concluded that the Singapore's stock market and the property index form co-integrating relationship with changes in the short and long-term interest rates, industrial production, price levels, exchange rate, and money supply (5). The multifactor model in the USA by employing seven macroeconomic variables revealed that consumption, oil prices and the market index are not priced by the financial market. However, industrial production, changes in risk premium and twists in the yield curve are found to be significant in explaining stock returns (6).

Findings from the second study covering the USA suggested that future market stock returns could be forecasted by interpreting macroeconomic variables such as default spread, IP growth rate, term spread, one-month t-bill rate, and the dividend - price ratio (7). Another study was carried out examining the causal relation between stock returns and macroeconomic variables in Norway. Results showed a positive linkage between oil price and stock returns as well as real economic activity and stock returns. The study, however, failed to show a significant relation between stock returns and inflation (8). The vector error correction approach was used to model the relationship between Japanese stock returns and macroeconomic variables. Cointegration relation was detected among stock prices and the six macroeconomic variables, namely exchange rate, inflation rate, money supply, real economic activity, long-term government bond rate and call money rate (9). It was determined whether macroeconomic variables, in particular, money supply and the budget deficit are important in predicting stock prices in Taiwan, Hong Kong, Singapore and South Korea. The results are broadly consistent 
with the general economic literature on macroeconomics and suggest that there exists a long-run equilibrium relationship between macroeconomic policies, and stock prices for the four countries studied; stock prices do not necessarily adjust quickly and fully to changes in either monetary or fiscal policies, in the short run (10).

Relationships among selected macroeconomic variables and the Indian stock market were analyzed. By employing a vector error correction model, we find that three long-term equilibrium relationships exist among these variables. Our results suggest that domestic inflation is the most severe deterrent to Indian stock market performance, and domestic output growth is its predominant driving force. After accounting for macroeconomic factors, the Indian market still appears to be drawn downward by a residual negative trend. We attribute this to economic mismanagement, since the size of the downward pull mitigates after 1990, coinciding with the beginning of Indian economic reforms. (11)

Several factors such as political instability, low-growth rate, lack of entrepreneurship and inadequate demand for stocks as some of the factors that are likely to influence the performance of the GSE. The study projected massive growth of the stock exchange in terms of demand and supply provided the economic and political conditions remained favorable. (12)

Investigation was carried out to measure the extent to which global and local economic factors explain returns in emerging stock markets (ESMs). The economic factors are determined using principal components analysis. The results suggest that the local economic variables included in this study can be summarized by GDP, inflation, money and interest rates, while the selected global variables can be sufficiently characterized by world industrial production and world inflation. These components are then used as inputs into a regression analysis in order to explain the index returns of 13 ESMs over the period 1987-96. The analysis indicates that while world factors are significant in explaining ESM returns, local factors may also play a crucial role. (13)

\section{Conclusion}

The paper investigates the extent to which local macroeconomic variables and political condition explain the stock price movements in Dhaka Stock Exchange. It is observed that political instability doesn't play any significant role in determining the movements in the general index. Investors seem to be comfortable and to some extent habituated to our political situation. However, macroeconomic variables have a significant and deterministic impact. By principles, it can be expected that the index will rise with the increase in money supply, remittance and decrease in the interest rate spread. Correlation analysis complies with this expectation. We can observe that inflation rate and exchange rate are positively correlated with DGEN. Additionally, the DSE general index can be estimated by the macroeconomic variables; both linearly and non-linearly. Economic models derived from regression analysis are significant in both cases. Although, binomial model can explain more than $80 \%$ of the variances in the general index while the linear model explains less than $30 \%$ of the variances. So definitely the binomial model is a better estimator. Another interesting, but not unexpected finding is that when we remove five observations from our dataset when the massive stock market crash in our country's history occurred, correlation analysis shows extremer relationships and economic models explain more of the variances. Although we cannot reach any definitive conclusion from this kind of indirect observation, it can be assumed that something happened during the time which is beyond economic causation. However, presence of this kind of causal relationship between stock index and macroeconomic variables puts the efficient market hypothesis in doubt. Policy makers should think twice before they make policies and make sure if they really want to affect the capital market. Ergo, dynamic interactions between macroeconomic variables and stock prices are important in the formulation of the nation's macroeconomic policy.

\section{References}

[1] Investopedia (2014). Definition of stock market. Retrieved from http://www.investopedia.com/terms/s/stockmarket.asp

[2] Bailey, W., \& Peter, YC. (1996). Risk and return in the Philippine equity market: a multifactor exploration, J. Pacific-Basin, 4: 197-218.

[3] Chung, S. K., \& Shing, TS. (1999). Co integration and causality between macroeconomic variables and stock market returns, J. Global Finance, 10: 7181.

[4] Ibrahim, M. H., \& Aziz, H. (2003). Macroeconomic variables and the Malaysian equity market: a view through rolling subsamples, J. Econ. Stud., 30: 6-27.

[5] Chen, N., Richard, R., \& Stephen, AR. (1986). Economic forces and the stock market. J. Bus., 59: 383-403.

[6] Chen, N. (1991). Financial investment opportunities and the macroeconomic, J. Finance, 46: 529-554.

[7] Cooper, B. (2004). Stock prices, inflation and stock returns predictability, J. Finance, 70(1): 63-84.

[8] Gjerde, O., \& Saettem, F. (1999). Causal relations among stock returns and macroeconomic variables in a small, open economy, J. Int. Financial Markets, Inst. Money, 9: 61-74.

[9] Mukherjee, TK., Naka, A. (1995). Dynamic Relations between Macroeconomic Variables and the Japanese Stock Market: An Application of a Vector Error Correction Model, J. Financial Res. 18:223-237.

[10] Chuang, Y. L., Ming W. L., \& Chih W. L. (2007). On Stock Market and Macroeconomic Variables: Evidences from Four Asian Tigers, ICICIC '07, IEEE, DOI: 10.1109/ICICIC.2007.419

[11] Naka, A., Mukherjee, T., \& Tufte, D. (1998) "Macroeconomic variables and the performance of the Indian Stock Market;". Department of Economics and Finance Working Papers, 1991-2006. Paper 15. http://scholarworks.uno.edu/econ_wp/15 
[12] Singh, T., Mehta, S., \& Varsha, M.S. (2011). Macroeconomic factors and stock returns: evidence from Taiwan. Journal of Economics and International Finance Vol. 2(4), pp.217-227.
[13] Fifield, S. G. M., Power, D. M. \& Sinclair, C. D. (2002) Macroeconomic Factors and Share Returns: an analysis using emerging market data, Int. J. Fin. Econ. 7: 51-62, DOI: $10.1002 /$ ijfe. 173 